\title{
AKTIVITAS ANTIOKSIDAN EKSTRAK Andrographis paniculata (Burm.f.) Ness DENGAN DUA PERBEDAAN PENGUAPAN
}

\section{ANTIOXIDANT ACTIVITY of Andrographis paniculata (Burm.f.) Ness EXTRACT DEPENDS ON TWO EVAPORATION DIFFERENCE}

\author{
Ichwan Ridwan Rais \\ Fakultas Farmasi Universitas Ahmad Dahlan \\ Jl. Prof.Dr. Soepomo, Yogyakarta, Telp. (0274) 379418 \\ Email: ichwanridwanrais@yahoo.co.id
}

Submitted: 08-12-2015

Reviewed: 05-03-2016

Accepted: 26-04-2016

\begin{abstract}
ABSTRAK
Andrographis paniculata (Burm.f.) Ness atau sambiloto adalah tanaman obat asli Indonesia yang megandung flavonoid. Senyawa ini memiliki potensi sebagai antioksidan, antibakteri, dan antiinflamasi. Antioksidan peka terhadap cahaya dan panas. Panas dan oksidasi dapat mempengaruhi aktivitas antioksidan flavonoid. Faktor panas dapat kita temui saat menguapkan pelarut menggunakan penguap konvensional dengan panas untuk mendapatkan ekstrak kering. Salah satu alat model ini adalah rotary evaporator. Cara penguapan lain, liofilisasi adalah alternatif untuk menguapkan pelarut tanpa pemanasan. Cara ini menggunakan alat yang dikenal freeze dryer. Telah dilakukan penelitian pengaruh perbedaan dua cara penguapan ekstrak sambiloto pada aktivitas antioksidan menggunakan metode penentuan nilai $\mathrm{IC}_{50}$ penghambatan aktivitas oksidan DPPH. Hasilnya menunjukkan cara penguapan freeze dryer dengan rendemen ekstrak $17,06 \%$ dan nilai $\mathrm{IC}_{50}$ sebesar $585,730 \mu \mathrm{g} / \mathrm{mL}$ lebih baik dibanding rotary evaporator dengan rendemen $24,96 \%$ dan $\mathrm{IC}_{50}$ sebesar $792,196 \mu \mathrm{g} / \mathrm{mL}$ dalam kemampuan menguapkan pelarut dan aktivitas antioksidan.
\end{abstract}

Kata kunci: flavonoid, rotary evaporator, freeze dryer, Andrographis paniculata (Burm.f.) Ness

\begin{abstract}
Andrographis paniculata (Burm.f.) Ness is one of the native tradisional medicine in Indonesia which contain active flavonoid. It has potential activity as antioxidant, antibacterial, and inflammation. Antioxidant sensitive to light and heat. Flavonoid antioxidant activity could be decline by heat and oxidation. We can find these caution while evaporate the liquid solvent with heating in conventional evaporation to get dry extract. One of the conventional evaporation instrument is Rotary Evaporator. Other evaporation system, lyophillization is alternative to evaporate solvent without heat. This system uses instrument called Freeze Dryer. Present study about antioxidant activity influenced by two different evaporation using $\mathrm{IC}_{50}$ determination in $\mathrm{DPPH}$ oxidation proved that evaporation difference could change antioxidant ability. The result shows freeze dryer evaporation result with $17.06 \%$ of extract yield and $585.730 \mu \mathrm{g} / \mathrm{mL} \mathrm{IC}_{50}$ value better than rotary evaporator with $24.96 \%$ of extract yield and $792.196 \mu \mathrm{g} / \mathrm{mL}$ IC $_{50}$ value in solvent evaporate ability and antioxidant activity.
\end{abstract}

Keywords: flavonoid, rotary evaporator, Freeze Dryer, Andrographis paniculata (Burm.f.) Ness

\section{PENDAHULUAN}

Tanaman asli Indonesia banyak digunakan secara empiris untuk mengobati berbagai penyakit. Salah satu tanaman yang berkhasiat pengobatan adalah Andrographis paniculata (Burm.f.) Ness atau yang dikenal dengan sambiloto. Tanaman ini secara tradisional digunakan sebagai penyakit kencing manis, radang paru, radang dan luka infeksi (Sudarsono et.al., 2006). Penggunaan empiris sambiloto 
sebagai obat radang dan kencing manis menjadi fokus banyak peneliti. Akbar (2011) memaparkan dalam ringkasan aktivitas farmakologi $A$. paniculata baik secara in vitro maupun in vivo memiliki banyak khasiat diantaranya antioksidan, antiinflamasi dan antihiperglikemik. Herba sambiloto dengan kandungan senyawa flavonoid (Chao dan Lin, 2010) adalah senyawa fenolik yang memberikan warna spesifik dengan uap ammonia atau membentuk komplek dengan $\mathrm{AlCl}_{3}$ dan terdeteksi dalam larutan atau kromatogram. Komplek $\mathrm{AlCl}_{3}$ dengan flavonoid yang mengandung gugus aromatis terkonjugasi yang menunjukkan serapan yang kuat pada spektrofotometri (Harborne, 1996). Flavonoid berpotensi sebagai antioksidan berkaitan dengan aktivitasnya sebagai anti bakteri, anti inflamasi, dan anti alergi (Lipinski, 2011).

Senyawa dengan komposisi ikatan rangkap dapat mengalami dekomposisi dengan putusnya ikatan rangkap karena proses oksidasi dan diperkuat dengan adanya pemanasan (Gandjar dan Rohman, 2007). Oksidasi dan pemanasan umumnya terjadi saat penguapan pelarut menggunakan alat pemanas seperti rotary evaporator dan tangas air dalam proses mendapatkan ekstrak sebagai bahan uji penelitian. Cara lain penguapan pelarut tanpa pemanasan menggunakan alat freeze dryer, suatu metode penguapan dengan vaccum pada suhu $-53^{\circ} \mathrm{C}$ sampai $-105^{\circ} \mathrm{C}$ (Anonim, 2006). Penelitian ini dilakukan untuk mengetahui keterkaitan pengaruh pemanasan pada penguapan dengan aktivitas antioksidan. Penelitian ini melanjutkan pengkajian sambiloto dengan kandungan flavonoid yang berkaitan dengan aktivitas antioksidan. Penulis belum menemukan kajian perbedaan proses penguapan ekstrak sambiloto terhadap aktivitas antioksidan dalam penelusuran jurnal.

\section{METODE PENELITIAN Alat dan Bahan}

Alat yang digunakan oven memmert, tanur, halogen moisture Metler toledo, rotary evaporator Buchi, seperangkat alat kromatografi, spektrofotometer UV-Vis Shimadzu 1800 dan peralatan gelas yang lazim digunakan. Bagian tanaman yang digunakan adalah herbanya. Identifikasi tanaman dilakukan di Laboratorium Biologi, Fakultas MIPA, Universitas Ahmad Dahlan. Bahan yang digunakan adalah standar quersetin (Sigma), etanol, n-heksan, 1,1-diphenyl-2-picrylhydrazyl (DPPH), lempeng KLT F254.

\section{Jalannya Penelitian Pembuatan ekstrak}

Dua bagian serbuk kering herba sambiloto masing-masing sebanyak 125 gram dimaserasi menggunakan pelarut etanol $70 \%$ dalam wadah tertutup. Setelah proses maserasi, larutan hasil maserasi diuapkan menggunakan dua cara yang berbeda. Cara pertama menggunakan rotary evaporator pada suhu $50^{\circ} \mathrm{C}$ sampai mendekati konsistensi kental yang masih dapat dituang. Penguapan dilanjutkan diatas tangas air dengan suhu $50^{\circ} \mathrm{C}$ sampai didapat konsentrasi ekstrak kental selanjutnya disebut EP. Cara kedua menggunakan freeze dryer untuk menghilangkan pelarut tanpa menggunakan panas sampai didapat ekstrak kental agak kering pada suhu $-40^{\circ} \mathrm{C}$ selanjutnya disebut FD.

\section{Penetapan standar non spesifik dan spesifik ekstrak}

Identifikasi ekstrak dilakukan dengan menetapkan parameter non spesifik kadar air dan kadar abu serta parameter spesifik penetapan kadar kandungan flavonoid kedua ekstrak. Parameter non spesifik ditetapkan dengan menimbang sejumlah EP dan FD kemudian diukur kadar air menggunakan halogen moisture tester dan kadar abu menggunakan tanur. Penetapan parameter spesifik dilakukan dengan deteksi awal menggunakan kromatografi kertas dengan uap amoniak dan penetapan kadar flavonoid terhadap kuersetin menggunakan metode Chang (2002).

\section{Aktivitas antioksidan}

Sejumlah $50 \mathrm{mg}$ ekstrak EP dan FD dilarutkan dalam metanol dengan konsentrasi $10 \mathrm{mg} / \mathrm{mL}$ sebagai larutan induk. Analisis kualitatif dengan menotolkan larutan sampel pada kertas whatman, untuk menentukan bercak yang berpotensi antioksidan, disemprot menggunakan larutan DPPH dengan hasil positif berupa daerah berwarna kuning. Analisis kuantitatif dilanjutkan dibuat seri kadar sesuai hasil uji pendahuluan. $1 \mathrm{~mL}$ larutan sampel dimasukkan dalam tabung reaksi dan ditambahkan $1,0 \mathrm{~mL}$ 
DPPH kemudian diinkubasi selama 30 menit pada suhu kamar dan diukur pada panjang gelombang $517 \mathrm{~nm}$. Pembanding larutan quersetin dengan seri konsentrasi sesuai uji pendahuluan. Nilai IC50 ditentukan menggunakan rumus regresi linier (Erawati, 2012).

\section{Analisis Data}

Aktivitas antioksidan ekstrak EP dan FD ditentukan sebagai $\mathrm{IC}_{50}$. Nilai $\mathrm{IC}_{50}$ diperoleh dari nilai 50\% penghambatan terhadap DPPH dari kurva hubungan konsentrasi sampel vs persen penghambatan. Persen penghambatan terhadap DPPH dihitung menggunakan rumus:

$$
\left(\frac{A_{0}-A_{1}}{A_{0}}\right) \times 100
$$

$\mathrm{A}_{0=}$ absorbansi kontrol

$\mathrm{A}_{1=}$ absorbansi sampel

Signifikansi perbedaan potensi antioksidan kedua macam ekstrak terhadap standar flavonoid diuji dengan ANOVA.

\section{HASIL DAN PEMBAHASAN \\ Pembuatan ekstrak}

Ekstrak EP dan FD dibuat untuk mendapatkan dua macam ekstrak yang berbeda proses penguapannya. Pengamatan selanjutnya mengukur perbedaan perolehan rendemen dan aktivitas antioksidan karena perbedaan penguapan tersebut. Rendemen EP diperoleh sebesar 24,96\% dengan bobot ekstrak 31,20 gram dan rendemen FD sebesar 17,06\% dengan bobot ekstrak 21,33 gram (Gambar 1). Perbedaan hasil rendemen menunjukkan proses penguapan pelarut menggunakan freeze dryer lebih optimal dalam menghilangkan pelarut dari ekstrak. Organoleptis kedua ekstrak juga berbeda sebagaimana terlihat pada gambar 1, warna kecoklatan pada EP cenderung dominan dibanding FD yang terlihat kehijauan. Konsistensi EP lebih liat dan sulit dibagi, sedangkan FD berbentuk gumpalan-gumpalan kecil menempel yang lebih mudah dibagi.

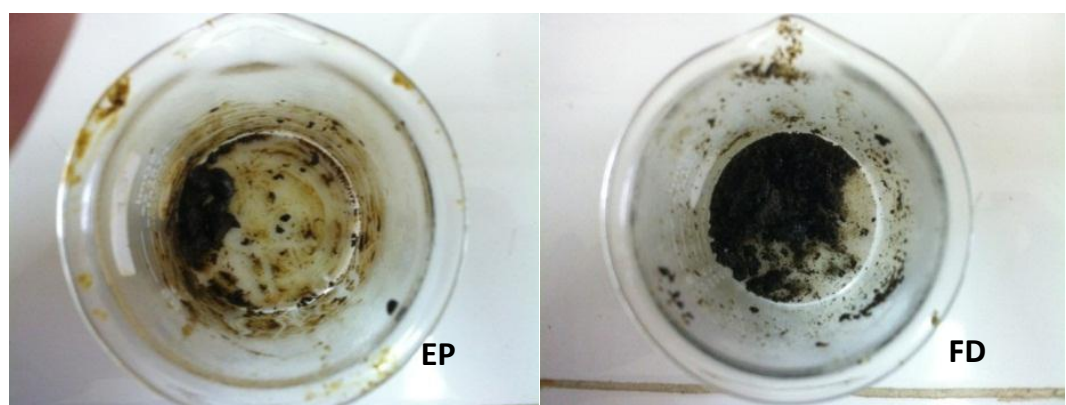

Gambar 1. Ekstrak hasil penguapan dengan Rotary evaporator (EP) dan Freeze Dryer (FD)

\section{Parameter standar non spesifik dan spesifik ekstrak}

Penetapan standar non spesifik kadar air ekstrak menghasilkan angka 7,59\% untuk EP dan nihil utuk FD, hal ini memperkuat bukti penguapan dengan freeze dry menghasilkan ekstrak yang lebih bebas pelarut. Penetapan kadar abu menunjukkan angka 13,20\% untuk EP dan 12,79\% untuk FD.

Penetapan standar spesifik ekstrak sambiloto dengan deteksi awal menggunakan kromatografi kertas terbukti mengandung flavonoid (Rais, 2015) yang ditandai dengan bercak kuning pada kromatografi kertas yang diuapi amoniak (Harborne, 1996). Deteksi flavonoid dalam EP dan FD menggunakan metode elusi KLT untuk memastikan kembali kandungannya. Elusi menggunakan fase diam kertas whatman dan fase gerak BAW (4:1:5) memperlihatkan bercak kuning pita flavonoid dari ekstrak setelah diuapkan amoniak seperti pada Gambar 2. 
Penetapan kandungan flavonoid ekstrak menggunakan standar kuersetin sebagai pembanding dan diperoleh hasil kadar 8,91\% untuk EP dan 12,212\% utuk FD. Data ini menunjukkan kandungan flavonoid dalam ekstrak yang diperoleh dengan freeze dry lebih besar.

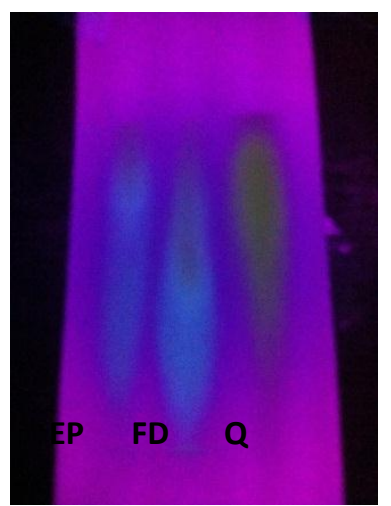

Gambar 2. Elusi deteksi kandungan flavonoid EP, FD dan Quersetin (Q) berwarna kuning setelah diuapkan dengan amoniak dibawah UV 366. FD kertas whatman, FG BAW (4:1:5)

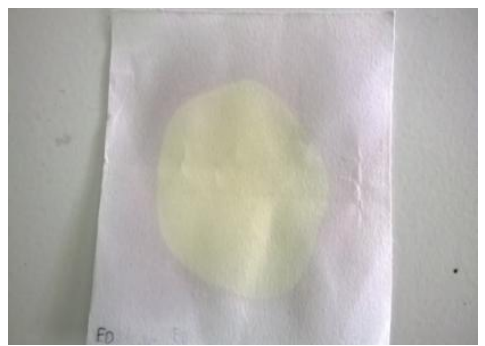

Gambar 3. Uji kualitatif aktivitas antioksidan larutan ekstrak disemprot dengan larutan DPPH menunjukkan warna kuning

\section{Aktivitas antioksidan}

Penentuan kuantitatif aktivitas antioksidan ekstrak EP dan FD menggunakan standar kuersetin. Konsentrasi seri kadar setiap larutan uji berdasarkan uji pendahuluan dengan ketentuan nilai absorbansi masuk dalam rentang 0,2 - 0,8 dengan tingkat kesalahan terkecil (Sumarno, 2013). Prosedur pembuatan larutan standar dan sampel yang akan diukur $\mathrm{IC}_{50}$-nya menggunakan metode Erawati (2012) yang dimodifikasi yaitu dengan mencampurkan $1 \mathrm{~mL}$ masing-masing larutan standar kuersetin, EP dan FD kedalam tabung reaksi berbeda ditambah $1 \mathrm{~mL}$ lautan DPPH. Setelah dikocok sampai homogen, kemudian diinkubasi selama 30 menit pada suhu kamar. Perbandingan nilai $\mathrm{IC}_{50}$ standar kuersetin, EP dan FD terhadap penghambatan DPPH menunjukkan perbedaan sebagaimana terlihat dalam Tabel I.

\begin{tabular}{lccc}
\multicolumn{4}{l}{ Tabel I. Nilai IC $_{\text {50 }}$ Standar kuersetin, EP dan FD terhadap DPPH } \\
& Kuersetin & EP & FD \\
\hline $\mathrm{IC}_{50}(\mu \mathrm{g} / \mathrm{mL})$ & 3,403 & 792,126 & 585,730 \\
\hline
\end{tabular}

Perbedaan nilai $\mathrm{IC}_{50}$ diatas terbukti berbeda bermakna $(\mathrm{p}<0,05)$ dengan uji ANOVA. Akbar (2011) memaparkan dalam ringkasan aktivitas farmakologinya bahwa sambiloto memiliki khasiat sebagai antioksidan. Aktivitas antioksidannya ditunjukkan oleh kandungan senyawa flavonoid (Chao dan Lin, 2010) yang berpotensi sebagai antioksidan. Struktur flavonoid terdiri dari dua cincin aromatis yang dapat atau tidak dapat menyusun cincin ketiga dengan kerangka struktur $\mathrm{C}_{6}-\mathrm{C}_{3}-\mathrm{C}_{6}$. Cincin aromatisnya terkonjugasi dan menunjukkan serapan yang kuat pada spektrofotometri (Harborne, 1996), sedangkan senyawa dengan komposisi ikatan rangkap dapat mengalami dekomposisi dengan putusnya ikatan rangkap karena proses oksidasi dan diperkuat dengan adanya pemanasan (Gandjar dan Rohman, 2007). Panas dan oksidasi yang terjadi selama proses pembuatan ekstrak diduga menjadi 
penyebab lemahnya nilai $\mathrm{IC}_{50}$ atau daya hambat EP terhadap aktivitas oksidan DPPH. Meskipun berbeda bermakna, secara umum aktivitas antioksidan kedua macam ekstrak termasuk dalam kategori antioksidan lemah. Menurut Armala (2009) potensi antioksidan kuersetin masuk dalam kategori sangat kuat $(<50 \mu \mathrm{g} / \mathrm{mL})$, sedangkan sampel EP dan FD masuk kedalam kategori lemah $(>150 \mu \mathrm{g} / \mathrm{mL})$.

Hasil perbandingan langsung beberapa parameter antara EP dan FD terlihat pada Tabel II dan kurva perbandingan aktivitas antioksidannya terlihat pada Gambar 4.

Tabel II. Perbandingan beberapa parameter ekstrak EP dan FD dan aktivitas antioksidannya terhadap DPPH

\begin{tabular}{lcc}
\hline Parameter & EP (Evaporator) & FD (Freeze Dryer) \\
\hline Rendemen & $24,96 \%$ & $17,06 \%$ \\
Kadar air & $7,59 \%$ & $0 \%$ \\
Kadar abu & $13,20 \%$ & $12,79 \%$ \\
Kandungan flavonoid & $8,91 \%$ & $12,212 \%$ \\
Nilai $\mathrm{IC}_{50}$ & $792,126 \mu \mathrm{g} / \mathrm{mL}$ & $585,730 \mu \mathrm{g} / \mathrm{mL}$ \\
\hline
\end{tabular}

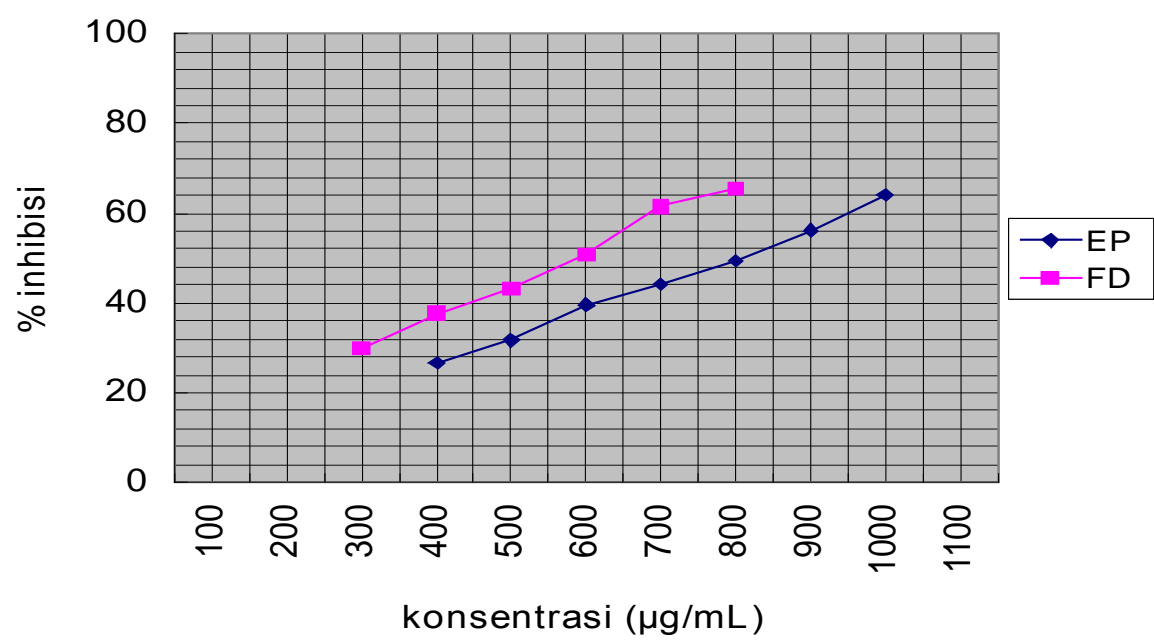

\section{Gambar 4. Kurva perbandingan aktivitas antioksidan konsentrasi EP dan FD vs persen penghambatan DPPH.}

Sesuai dengan penelitian sebelumnya (Rais, 2015), sambiloto dengan kandungan flavonoid aktif terbukti memiliki aktivitas farmakologi antioksidan yang dapat saja berkaitan dengan mekanisme seluler patologi penyakit degeneratif seperti diabetes dan penyakit hormonal yang lebih kompleks seperti sindrom polisistik ovari (PCOS).

\section{KESIMPULAN}

Terdapat perbedaan yang signifikan jumlah rendemen dan nilai $\mathrm{IC}_{50}$ penghambatan oksidan DPPH oleh ekstrak etanolik sambiloto yang diuapkan dengan rotary evaporator dan freeze dryer meskipun keduanya masuk katagori lemah. Hasil ini membuktikan freeze dryer memberikan proses penguapan pelarut ekstrak sambiloto dan aktivitas antioksidan yang lebih baik dalam menghambat oksidan DPPH.

\section{UCAPAN TERIMAKASIH}

Penelitian ini dibiayai oleh Lembaga Penelitian dan Pengembangan Universitas Ahmad Dahlan tahun anggaran 2015. 


\section{DAFTAR PUSTAKA}

Akbar, S. 2011. Andrographis paniculata: A Review of Pharmacological Activities and Clinical Effects. Journal of AMR,16(1):66-77.

Anonim, 2006, Operator's Instruction Manual Bench Top Freeze Dryers, Manual Book, Virtis New York, USA. hal 34.

Armala, M. M., 2009, Daya Antioksidan Fraksi Air Ekstrak Herba Kenikir (Cosmos caudatus H. B. K.) dan Profil KLT, Skripsi, 39, Fakultas Farmasi Universitas Islam Indonesia, Yogyakarta.

Chang, CC., Yang MH., Wen, HM., and Chern, JC., 2002, Estimation of Total Flavonoid Content in Propolis by Two Complementary Coloric Methodes, Journal of Food and Drug Analysis, Vol 10, No 3, 2002, p.178-182.

Chao, WW. and Lin, BF. 2010. Isolation and Identification of Bioactive Compounds in Andrographis paniculata (Chuanxinlian). Chinese Medicine Journal. 5:1-15.

Erawati, 2012, Uji Aktivitas Antioksidan Ekstrak Daun Garcinia daendalanthera Pierre Dengan Metode DPPH dan Identifikasi Golongan Senyawa Kimia Dari Fraksi Paling Aktif, Skripsi, UI Jakarta.

Gandjar, IG. dan Rohman, A. 2007. Kimia Farmasi Analisis. Cetakan I. Pustaka Pelajar. Jogjakarta. Hal 42.

Harborne, JB. 1996. Metode Fitokimia. Penuntun Cara Modern Menganalisis Tumbuhan. Edisi kedua. diterjemahkan oleh Kosasih Padmawinata dan Iwang Soediro. Penerbit ITB. Bandung. hal 93.

Lipinski, B. 2011. Hydroxyl Radical and Its Scavengers in Health and Disease. Review Article. Oxidative Medicine and Cellular Longevity. 11:1-9.

Rais, IR. 2015. Isolasi dan Penentuan Kadar Flavonoid Ekstrak Etanolik Herba Sambiloto Andrographis paniculata (Burm.f.) Ness. Pharmaciana. Vol.5 No.1. 101-107.

Sudarsono, Pudjoarinto, A., Gunawan, D., Wahyuono, S., Donatus, IA., Drajad, M., Wibowo, S., Ngatidjan. 2006. Tumbuhan Obat 1. Pusat Penelitian Obat Tradisional. Universitas Gadjah Mada. Yogyakarta. hal 25-28.

Sumarno, 2013, Analisis Kimia Instrumen, Materi Kuliah, UAD Jogjakarta. hal 6. 